nascent hydrogen obtained in this way is very active in penetrating the palladium. At $0^{\circ} \mathrm{C}$., the thermoelectric power of the palladium, after being exposed to nascent hydrogen, was in one ease only 28 per cent. of the value for the gas free metal. The process of filling with hydrogen by the electrolytic method and then removing the gas by heating in vacuo to about $700^{\circ} \mathrm{C}$. was repeated several times and each time the thermoelectric power was lowered by about the same amount as a result of the absorption of the gas and restored to the original gas free value upon removal of the hydrogen.

To obtain the largest effects it was necessary to use the palladium soon after it had been exposed to the hydrogen as the gas slowly diffused away from the metal over a period of several days. Also if the region containing the temperature gradient of the gas filled strip were heated during a determination of thermo e $\mathrm{m} \mathrm{f}$, the result was a removal of the hydrogen and a restoration to the original gas free value of thermoelectric power. During a determination of thermo e $\mathrm{m} f$ the conduction of heat from the hot junction along the palladium strip caused the evolution of some of the gas and for the higher temperatures of the hot junction the thermoelectric power approached that for the gas free metal.

These results show that a monometallic circuit consisting of gas free and gas filled palladium will give rise to a thermo e $\mathrm{m} f$ when the junctions are at different temperatures. Since palladium is negative at the cold junction of a palladium-platinum couple, and since the absorption of hydrogen eauses a reduction in thermoelectric power, it follows that gas filled palladium is positive to the gas free metal at the cold junction. Data obtained for one ease in which the palladium was electrolytically filled give the value of the thermo e $\mathrm{m} f$ in such a monometallic circuit as: $\mathrm{E}=0.120-$ $0.000230^{\circ}$, where $\theta$ is the temperature of the hot junction, the cold junction being to $0^{\circ} \mathrm{C}$. The constants will depend upon how completely the palladium is filled with hydrogen.

According to the electron theory of thermoelectricity the thermoelectric power (e) of a couple is given by the expression: $e=K \log \frac{n_{\mathrm{a}}}{n_{\mathrm{b}}}$, where $K$ is a constant, $n_{\mathrm{a}}$ and $n_{\mathrm{b}}$ are the effective electron densities in the two materials forming the circuit. When $n_{\mathrm{a}}$ is larger than $n_{\mathrm{b}}$ the current flows from material $a$ to material $b$ at the cold junction. The effect of absorbed hydrogen, then, is to increase the effective electron density in palladium.

R. M. Hotimes

$$
\begin{aligned}
& \text { Department of Physics, } \\
& \text { Corneli Universint } \\
& \text { June } 10,1922
\end{aligned}
$$

\section{THE EFFECT OF SPERM BOILED IN OXA- LATED SEA-WATER IN INITIATING DEVELOPMENT}

Is connection with certain experiments (the results of which have not yet been published) that were made in an attempt to analyze the rôle of calcium in the fertilization of the egg of Nereis, the following results were obtained: (1) Nereis sperm that have been treated with oxalated sea-water are capable of fertilizing normal Nereis eggs; (2) Nereis eggs treated with oxalated sea-water are capable of fertilization with normal Nereis sperm; (3) Eggs of Nereis are capable of fertilization in oxalated sea-water. Such eggs form jelly, maturate, cleave and give rise to swimming larvæ in the oxalated sea-water. These larvæ show a varying per cent. of abnormalities; (4) Uninseminated Nereis eggs treated with oxalated seawater ( 0.5 per cent. and above of sodium or potassium oxalate in sea-water) form swimming larvæ which show differentiation without cleavage; (5) Sperm of Nereis boiled in 0.1 per cent. to 0.25 per cent. sodium or potassium oxalate in sea-water are capable of initiating development in the egg of Nereis. This last result may be briefly considered.

Uninseminated eggs of Nereis obtained by eutting a dry female are exposed to each of three boiled sperm suspensions. These boiled sperm suspensions are made up as follows: one drop of dry sperm in 5 ec of sea-water; one drop of dry sperm in 5 ce of $0.53 \mathrm{M} \mathrm{NaCl}$; and one drop of dry sperm in 5 ce of 0.1 to 0.25 per cent. sodium or potassium oxalate in sea-water. In each ease the drop of sperm is carefully placed in the bottom of a test tube and the solution added. The test tube is then quickly brought to the boiling point over a flame and the suspension is kept at the boiling 
point for three minutes. To avoid any possibility of living sperm being present, the wall of the tubes are thoroughly flamed. The tubes, together with one containing normal sea-water kept at the boiling point for three minutes, are then set aside to be used after from two to twenty-four hours. For an experiment ten drops of each suspension and ten drops of the boiled sea-water are placed in dishes each containing one drop of dry eggs. Two minutes later to each dish are added ten ec of seawater. A control, uninseminated eggs in normal sea-water, was always kept. If the control showed jelly formation the experiment was discarded.

Uninseminated eggs of Nereis exposed to these boiled sperm suspensions and to boiled sea-water in this way give the following results: boiled sea-water, no development; sperm boiled in sea-water, no effect beyond small per cent. of jelly formation, maturation and differentiation without cleavage; sperm boiled in oxalated sea-water, higher per cent. of differentiation without cleavage. The highest per cent. of swimming larvæ (differentiation without cleavage) ever obtained with the $\mathrm{NaCl}$ boiled sperm was about 10 per cent.; the highest with oxalated sperm was 32 per cent. And this proportion usually holds.

The first experiment of this kind was made early in June, 1914. At Dr. F. R. Lillie's suggestion these experiments were repeated directly under his supervision in his laboratory at the Marine Biological Laboratory, Woods Hole, Mass., during each Nereis "run" of 1915 . It gives me great pleasure to acknowledge my indebtedness to him for many helpful suggestions in this work.

Every possible precaution was taken against contamination; every variation in procedure to be thought of was tried; and throughout one season, whenever Nereis eggs were to be had, the experiments were studiously repeated. Despite the precautions and the laborious repetitions, both during 1915 and subsequent seasons, it is impossible to reduce the results to any seeming order. Even after the elimination of certain sources of error the results are ineonstant. The sources of error may be mentioned:
1. Failure to use perfectly fresh eggs of high cortical sensitivity. In $1915 \mathrm{I}$ had great difficulty in keeping the worms from shedding their eggs wher kept in the laboratory over night. I therefore adopted the plan of keeping the animals in the refrigerator. But this only made matters worse, for the females shed very quickly on removal from the low temperature. Such eggs were of little value. Moreover, if transfer from the cold sea-water to that at room temperature be suddenly made not only are the eggs shed but they are induced to form jelly and maturate. Moreover, eggs from animals that have been kept at low temperature are not best for study of cortical changes. Such eggs are apt to be polyspermic and in other ways give evidence of change in the cortical reaction. I have found that keeping Cumingia (dry) in the refrigerator markedly changes the normal cortical reactions. The eggs of both forms kept in this way give good cleavage and swimmers, but they do not give the best cortical reactions. For the work with sperm boiled in oxalated sea-water, then, one must have fresh eggs taken from dry females.

2 . The oxalated sea-water should not be more than twenty-four hours old when used. It is best not to use stock solutions. Various experiments were made with different molecular solutions of the oxalates in distilled water plus the addition of double sea-water to correct the hypotony. But the distilled water solutions seem to deteriorate. It was found best to add from 0.1 to 0.25 grams of the oxalate to 100 ce of sea-water which was filtered before use. But even with fresh eggs and the optimum oxalated sea-water the results are far from uniform.

Since hypertonic sea-water alone initiates development in the egg of Nereis, we might think that boiling the sea-water is alone responsible for the results. But boiled sea-water alone has no effect. Since oxalate in sea-water initiates development, we might argue that it is the oxalate in the sea-water rather than the dead sperm that initiates development. However, oxalate alone to call forth development must be present in greater amount than in the suspension of sperm boiled in oxalated seawater. 
My first thought in making these experiments was that ealcium is necessary for fertilization on the assumption that in some way it holds intact a substance loosely bound to the sperm head which makes possible the reaction of the sperm with the egg. Calcium free sea-water, then, would bring about the loss of this substance and thus render fertilization impossible. If, however, fertilization takes place in oxalated sea-water, this assumption is untenable.

On the basis of Robertson's work, which indicates that "fertilizing" substance can not be extracted in presence of calcium, we might conclude that the Nereis experiments here cited show that the effect of boiling sperm in oxalated sea-water is to extract a fertilizing substance from the sperm. This I do not believe and for several considerations.

Though hypertonicity is not responsible for the results here reported, nevertheless, boiling must certainly increase the salt content of the oxalated sea-water. Again, any amount of oxalate present above that necessary to remove calcium must increase on boiling. Moreover, in the sea-water itself chemical changes ensue through boiling. And finally, on boiling, the sperm perhaps lose specificity-they act as any foreign colloid which may induce development.

The results here reported might thus be due to the total of these several factors each of which alone is incapable of calling forth development. I conclude, therefore, that the results here reported do not indicate that they are due to a fertilizing substance extracted frọm the sperm.

E. E. Just

Marine Biological Laboratory, Woods HoLe, Mass.

\section{THE WESTERN SOCIETY OF NATURALISTS}

THE annual meeting of the Western Society of Naturalists was held in Salt Lake City, Utah, June 22-23, 1922, during the convocation of the Pacific Division, American Association for the Advancement of Science. Presiding officers were Dr. F. B. Sumner, president, and Dr. J. F. MeClendon, secretary pro tem.

The following offlcers were chosen at the annual election: H. S. Reed, president; Chester Stock, vice-president, and C. O. Esterly, secretary.

The program presented was as follows:

JUNE 22

PHYSTOLOGICAL PAPERS

The occurrence of essential oils in desert plants: MAXWELL ADAMS.

The infuence of temperature upon the germination of orange sced: H. S. FAWCETT.

Influence of gravity on the development of new growth on horizontal shoots: F. F. HALma.

Mitosis in rhizopods and flagellates: C. A. KoFOID.

Longevity of Artemia in natural and artificial brines: E. G. MARTiN.

Some quantitative aspects of growth: H. S. REED.

Dendograph record of the redwood (with lantern slides): D. T. MAcDougaL.

The occurrence of goitre in relation to the distribution of iodine: J. F. MCCLENDON.

\section{HERUDITY AND EVOLUTION}

The two chromosomes of Clarkia: L. L. BurLINGAME.

Inheritance of flower color in Clarkia: L. L. BurLingame.

The law of geminate speoies: D. S. JORDAN.

Theories as to the mode of evolution: J. P. Lotsy.

The origin and interitance of specific characters: F. B. SUMNER.

Darwinism-an analysis by observation and experiment: W. L. Tower.

$$
\text { JUNE } 23
$$

PAPERS READ IN JOINT SESSION WITH THE ECOLOGICAL SOCIETY OF AMERICA

The original grasslands of California: F. E. Clements.

Why not conserve the marine mammals of the Pacific? B. W. EvermanN.

Factors limiting the distribution of Teredo navalis in San Francisco Bay: C. A. RoFord.

Climate of the Inland Empire in relation to silviculture and forest fires: J. A. LARSEN.

Food and game fishes of the Snake River, Great Basin: S. B. Locke.

Wild bird life of the rookeries on the islands of Great Salt Lake (with motion pictures): C. G. Plummer.

A bog forest near Victoria: G. B. RIGG.

Chester Stock, Secretary 